\title{
“TRADUCCIONES LOCALES DE LA INCLUSIÓN EDUCATIVA PARA JÓVENES Y ADULTOS: un estudio en la provincia de Córdoba,
} Argentina"

\author{
María Alejandra Bowman'
}

\section{RESUMEN}

Este artículo expone resultados de una tesis doctoral sobre un programa de empleo para jóvenes desarrollado en la provincia de Córdoba, desde su componente de finalización de estudios obligatorios. También recupera análisis realizados en el marco de un estudio posdoctoral que aborda las políticas de inclusión educativa en Argentina. Estos estudios utilizaron una metodología cualitativa de corte etnográfico. En el artículo se desarrolla un abordaje general sobre las políticas orientadas a la inclusión educativa en Argentina entre 2003 y 2015, las principales transformaciones producidas a partir del principio de inclusión social y su traducción política a través de múltiples normativas en el ámbito educativo. En ese marco, se realiza una aproximación a la Educación de Jóvenes y Adultos y su articulación a un programa de empleo. Seguidamente, se describen las principales problemáticas que emergieron en torno a la inclusión educativa desde una experiencia concreta en una escuela de jóvenes y adultos.

Palabras clave: Inclusión Educativa. Jóvenes. Adultos.

\section{"TRADUÇÕES LOCAIS DE INCLUSÃO EDUCACIONAL PARA JOVENS E ADULTOS:}

\section{um estudo da província de Córdoba, Argentina"}

\section{RESUMO}

Este artigo expõe os resultados de uma tese de doutoramento sobre um programa de emprego para os jovens desenvolvido na província de Córdoba, desde sua conclusão do componente obrigatório de estudos. Também recupera análises efetuadas no âmbito de um estudo de pós-doutorado que aborda a política de inclusão educacional na Argentina. Para o estudo utilizou-se uma metodologia qualitativa de corte etnográfico. No artigo desenvolveu-se uma abordagem geral sobre as políticas da inclusão educacional na Argentina entre 2003 e 2015, observou-se grandes transformações produzidas a partir do princípio da inclusão social e a sua tradução política através de vários regulamentos no domínio da educação. Neste contexto, desenvolveu-se uma abordagem para a educação de

\footnotetext{
1 Licenciada y Doctora en Ciencias de la Educación. Becaria posdoctoral del Consejo Nacional de Investigación, Ciencia y Tecnología (CONICET). Institución de pertenencia: CONICET - Instituto de Humanidades. Universidad Nacional de Córdoba. Córdoba, Argentina. E-mail: mariaalebow@gmail.com
} 
jovens e adultos e sua articulação para um programa de emprego. Em seguida, descreveu os principais problemas que surgiram em torno da inclusão educacional por meio de uma experiência concreta em uma escola para jovens e adultos.

Palavras-chave: Inclusão Educacional. Jovens. Adultos.

\title{
"LOCAL TRANSLATIONS OF EDUCATIONAL INCLUSIÓN FOR YOUTH AND ADULTS: a study in the province of Córdoba, Argentina"
}

\begin{abstract}
This article presents the results of a doctoral thesis on an employment program for young people developed in the province of Cordoba, from their compulsory studies completion component. It also recovers analysis carried out within the framework of a postdoctoral study which deals with the policy of inclusive education in Argentina. These studies used a qualitative methodology of ethnographic court. The article develops a general approach on policies aimed at educational inclusion in Argentina between 2003 and 2015, major transformations produced from the beginning of social inclusion and its political translation through multiple regulations in the field of education. In this context, is an approach to the education of young people and adults and its articulation to an employment programme. From there, the main problems that emerged around inclusive education from a concrete experience in a school for youth and adults are described.
\end{abstract}

Keywords: Educational Inclusion. Youth. Adults.

\section{INTRODUCCIÓN}

El presente artículo expone resultados de una tesis doctoral ${ }^{2}$ sobre el componente educativo de un programa de empleo para jóvenes desarrollado en la provincia de Córdoba. Asimismo, recupera análisis realizados en el marco de un estudio posdoctoral ${ }^{3}$ que aborda las políticas de inclusión educativa y la educación de jóvenes y adultos en Argentina.

La investigación doctoral asumió dos grandes propósitos: el estudio de las políticas públicas para jóvenes orientadas a la formación laboral y la educación básica, y el estudio en caso de la primera experiencia del Programa Jóvenes Con Más y Mejor Trabajo (Programa Jóvenes) en la provincia de Córdoba, durante el año 2009.

\footnotetext{
2 "La Formación laboral y la educación básica en jóvenes de baja escolaridad" (2015). Universidad Nacional de Córdoba. CONICET.

3 "Educación y Trabajo en la modalidad de jóvenes y adultos. Un abordaje desde los nuevos formatos de la política de inclusión educativa". CONICET.
} 
La investigación posdoctoral se enfoca en los nuevos formatos de la política de inclusión educativa en la Educación de jóvenes y adultos, desde el análisis de los lineamientos políticos (nacionales y provinciales), y el estudio de una experiencia local en una escuela de jóvenes y adultos de Córdoba, donde conviven distintos programas socio-educativos. Ambos estudios utilizaron una metodología cualitativa de corte etnográfico.

El artículo desarrolla - en primer lugar - un abordaje general sobre las políticas orientadas a la inclusión educativa en Argentina entre 2003 y 2015 , las principales transformaciones producidas a partir del principio de inclusión social y su traducción política a través de múltiples normativas que extendieron la obligatoriedad escolar y se enfocaron en desarrollar estructuras y dispositivos diferentes en el tránsito de niños, jóvenes y adultos por la escolaridad.

En segundo lugar, se realiza una aproximación a la Educación de Jóvenes y Adultos en su dimensión política y normativa de los últimos años, para analizar -en ese marco- su articulación a un programa de empleo. Posteriormente, se describen las principales problemáticas que emergieron en el estudio sobre una experiencia local en una escuela de jóvenes y adultos.

Finalmente, se analizan algunos mecanismos selectivos de la institución escolar que forman parte de un engranaje que funciona a partir de la naturalización de condiciones y prácticas que borran la incidencia de éstas sobre las trayectorias escolares de jóvenes y adultos, y se establecen consideraciones de cierre en torno a la discusión sobre los procesos de "inclusión" que configuran itinerarios escolares desiguales, produciendo nuevas exclusiones.

\section{LAS POLIITICAS ORIENTADAS A LA INCLUSIÓN EDUCATIVA EN ARGENTINA}

En el contexto actual argentino, bajo la gestión de un nuevo gobierno nacional desde el 10 de diciembre de 2015, la educación y la ciencia son parte de las variables de ajuste de un Estado que prescinde de ellas, para dejarlas en manos del mercado, bajo un proyecto de país fuertemente 
anclado en el neoliberalismo. El recorte presupuestario, el desmantelamiento de áreas y programas nacionales educativos, el cierre de postítulos nacionales para docentes, el incumplimiento de planes y acuerdos en ciencia y tecnología, entre otros problemas, ponen en evidencia el derrumbe de muchas de las estrategias que se llevaron adelante desde 2003 hasta 2015 a través de políticas estatales que tuvieron alto nivel de consenso en la comunidad (FILMUS, 2017).

El mapa completo del ajuste y el desmantelamiento de las políticas orientadas a la inclusión educativa de los gobiernos anteriores, apenas asoma en la discusión académica. Sabemos que los tiempos de implementación de políticas se diferencian de los tiempos de investigación, y aún resulta significativo poder revisar las políticas y estrategias de años precedentes para profundizar la mirada sobre las conquistas alcanzadas, su impacto en los sujetos y en los territorios locales de implementación, y desde allí realizar aportes para revisar las asignaturas que quedaron pendientes.

Los gobiernos nacionales entre 2003 y 2015, tuvieron como objetivo principal brindar educación de calidad, reubicando la función social de la educación en torno a cuatro ejes centrales: a) la construcción de la identidad nacional, b) el fortalecimiento de la democracia, c) la justicia y la igualdad social y d) la elevación de la productividad y el desarrollo científico tecnológico: "Estos objetivos tienen correspondencia con el modelo de desarrollo nacional que contempla a la distribución más justa de la riqueza como el motor del desarrollo y el crecimiento. Desde una concepción integral, los cuatro elementos contribuyen a diseñar una política que genere una función igualadora de la educación respecto del mundo del trabajo" (FILMUS, 2010, p.192).

Las principales normativas que regulaban el sistema educativo nacional durante los años 90, fueron modificadas a través de un proceso que se inició en el año 2005, con la sanción de la Ley de Educación Técnico Profesional No 26.068 (LETP), la Ley de Financiamiento Educativo № 26.075 (LF) y la sanción de la Ley de Educación Nacional N² 26.206 (LEN), en diciembre de 2006. 
A partir de 2007, el Instituto Nacional de Formación Docente (INFOD) puso en marcha la elaboración de planes de mejoramiento a fin de repensar las instituciones formadoras de futuros docentes. En el año 2008, se creó la Dirección Nacional de Políticas Socioeducativas con el propósito de promover políticas para la inclusión, igualdad y calidad educativa. Se trató de programas y proyectos que apuntaron al fortalecimiento de las trayectorias educativas de niños, niñas y jóvenes en contextos socioeconómicos vulnerables a través de la asignación de múltiples recursos necessários. En 2009, se creó por decreto presidencial4, la Asignación Universal por Hijo (AUH) que es una política social que otorga en una prestación monetaria no contributiva similar a la que reciben los hijos de los trabajadores formales y que incidió en la escolarización de los jóvenes ya que está condicionada a la asistencia escolar, el cumplimiento del calendario de vacunación obligatoria y a los controles anuales de salud.

En este proceso de transformación, hubo otras medidas específicas que acompañaron los propósitos de la inclusión educativa, como la de Garantía Nacional al salario docente, la fijación del ciclo lectivo en 180 días, la Ley para otorgar fondos y aumentar el incentivo salarial docente, la Ley de Educación Sexual y Salud Reproductiva, y la Ley de Protección Integral de Niños, Niñas y Adolescentes.

Las definiciones de la LEN tuvieron como correlato la necesidad de transformación de todo el sistema educativo, con el propósito de articulación entre los niveles y las modalidades educativas 5 .

La LEN introdujo la extensión de la escolaridad obligatoria incluyendo a todo el Nivel Secundario (ampliándola de 10 a 13 años). Para cumplir con este mandato de obligatoriedad, se dejó abierta la posibilidad de llevar a cabo experiencias que respondieran a las exigencias de los contextos a

\footnotetext{
${ }^{4}$ De la entonces presidenta Cristina Fernández de Kirchner (2007-2015).

5 La estructura comprendió 4 niveles: la Educación Inicial, la Educación Primaria, la Educación Secundaria y la Educación Superior. Y 8 modalidades: la Educación Técnico Profesional, la Educación Artística, la Educación Especial, la Educación Permanente de Jóvenes y Adultos, la Educación Rural, la Educación Intercultural Bilingüe, la Educación en Contextos de Privación de Libertad y la Educación Domiciliaria y Hospitalaria.
} 
través de alternativas institucionales, pedagógicas y de promoción de derechos, que se ajustaran a los requerimientos comunitarios, urbanos y rurales, mediante acciones que permitiesen alcanzar resultados de calidad equivalente en todo el país y en todas las situaciones sociales (LEN, Art.16).

La educación como derecho humano implicó políticas amplias que colocaron al Estado como primer responsable de la regulación de las prestaciones públicas educativas. El Estado Nacional desde la ley, se reservó la atribución de fijar la política educativa, controlar su cumplimiento con la finalidad de consolidar la unidad nacional, respetando las particularidades provinciales y locales, y asumió la responsabilidad de planificación, organización, supervisión y financiación el sistema educativo. Se reconoció como una responsabilidad principal e indelegable del Estado en materia educativa, dando lugar de manera concertada a la participación de las organizaciones sociales y las familias.

Se estableció como fin principal, la distribución equitativa de una educación de calidad garantizando "a todos/as el acceso y las condiciones para la permanencia y el egreso de los diferentes niveles del sistema educativo" (LEN, Art. 11, inciso i).

Estas orientaciones se tradujeron en normativas sobre la revisión de los formatos escolares, los dispositivos de evaluación, los contenidos curriculares -entre otros- con el fin de promover instancias y procesos de aprendizaje en diversos itinerarios y espacios formativos que tuvieran que ver con las necesidades e intereses de los estudiantes. En esas revisiones, la articulación de la educación al trabajo ocupó un lugar central.

Un estudio realizado por UNICEF (2012), sobre la implementación de la política de obligatoriedad de la educación secundaria en Argentina, sostiene que frente al mandato de la inclusión social y educativa, se desarrollaron políticas estatales que crearon múltiples programas sociales, laborales y educativos. También se realizaron una serie de modificaciones en espacios escolares, "flexibilizando" su "formato tradicional" y sus patrones de promoción, generando estructuras diferentes en el tránsito de niños, jóvenes y adultos por la escolaridad. El estudio señala que, atendiendo a las 
situaciones disímiles que viven los sujetos y respondiendo a la necesidad de introducir acciones diferenciadas, los gobiernos locales implementaron diversas políticas en pos de "reconvocar" a aquellos estudiantes que alguna vez estuvieron en la escuela y abandonaron.

En este sentido, con diversos formatos, supuestos, coberturas y financiamientos es posible mencionar a partir de 2004, las Escuelas de Reingreso (Ciudad Autónoma de Buenos Aires), los Centros de Escolarización para Adolescentes y Jóvenes (CESAJ, Provincia de Buenos Aires), el Programa de Inclusión/Terminalidad y Formación laboral de jóvenes de 14-17 años (PIT 14-17) en la provincia de Córdoba, o las propuestas nacionales como Plan Fines (Plan de Finalización de estudios Primarios y Secundarios), Volver a la escuela, los Centros de Actividades Juveniles (CAJs), los Centros de Actividades Infantiles (CAI), entre otros.

La expansión del nivel medio llevó a la creación de distintos "dispositivos de apoyo" para dar respuesta a las necesidades de los nuevos grupos poblacionales que fueron ingresando. El cambio de las "formas" en las que el Estado, a través de sus políticas, interpeló a las poblaciones tuvo un impacto en la "diferenciación social", no se trató sólo de distintas modalidades que intentaron integrarse en un mismo objetivo, sino que se trató cada vez más de "fragmentos" que cumplieron funciones sumamente distintas de acuerdo a los grupos poblacionales que atendieron (TIRAMONTI, 2008, 2011).

Ziegler (2011) manifiesta que los nuevos formatos escolares en el marco del mandato de inclusión y obligatoriedad, son dispositivos claves que implicaron el ingreso al nivel medio de jóvenes y adultos que antes no tenían acceso. De allí los "dispositivos ortopédicos" para albergar a este nuevo público: tutores, asesores pedagógicos, apoyo escolar, otras funciones docentes y otros programas que vienen en ayuda para promover la inclusión. Según la autora, uno de los riesgos centrales de este tipo de políticas es: generar una diferencia de experiencia sustancial para aquellos que las transitan a partir de la construcción de identidades diferenciales, que 
termina por encerrar en sus propios territorios lo que se visualiza como diverso, cristalizando así la fragmentación.

Las tensiones entre la cultura meritocrática y las propuestas de mejora y/o flexibilización curricular forman parte de un debate que atraviesa a las instituciones educativas y a sus agentes (inspectores, directivos, docentes, jóvenes, padres), sus discursos y sus prácticas. En este escenario, la inclusión trascendió la escuela secundaria común, donde la modalidad de jóvenes y adultos fue otra marca de época, ya que no sólo creció en estos años a ritmo vertiginoso sino que volvió a ocupar mayor centralidad en las agendas de política educativa, con diferentes formatos organizativos y actores en el territorio (KRICHESKY, 2014).

\section{LA EDUCACIÓN DE JÓVENES Y ADULTOS: respuestas a la inclusión y a la obligatoriedad educativa}

La Educación de Jóvenes y Adultos (EDJA) fue actualizando los debates estructurantes de su historia, reeditando la discusión sobre su importancia, su especificidad, la formación de sus docentes, los contenidos curriculares, la organización institucional, la vinculación con el mundo del trabajo, entre otros.

Históricamente, en la EDJA se concentraron demandas de atención específica de parte de múltiples entidades, tanto del sector de la producción, del empleo, de los sindicatos, de organizaciones de la sociedad civil. Varias alternativas se han ensayado a lo largo de los últimos 15 años para concretar una formación que forme parte de un proyecto educativo integral.

La relevancia dada a la articulación con sectores del mundo laboral y productivo, reeditaron las discusiones acerca de los sentidos que asume la EDJA en la formación para el trabajo de jóvenes y adultos atravesados por la desigualdad y la falta de oportunidades. Este eje es constitutivo de la modalidad, reivindicado y revitalizado desde las directrices internacionales y desde la política pública nacional y provincial a través de la creación de 
dispositivos y estrategias que promovieron convenios colaborativos y articulaciones de las acciones.

Desde el contexto internacional, en la VI Conferencia Internacional de Educación de Adultos realizada en Brasil (CONFINTEA VI, 2009), la EDJA se propuso como un espacio que necesita ocupar mayor atención en el discurso regional e internacional y en las acciones de la política educativa de los estados nacionales. Allí se expresó su centralidad para llevar adelante procesos de inclusión educativa: "La educación de adultos se reconoce como un elemento esencial del derecho a la educación y debemos trazar un nuevo y urgente curso de acción para posibilitar que todos los jóvenes y adultos ejerzan ese derecho" (CONFINTEA VI, Marco de Acción, 2009, p.2).

Se reforzó en dicha instancia, la idea fundamental de que la educación de adultos atiende a las necesidades de aprendizaje de los jóvenes, los adultos y los mayores, abarcando una amplia gama de contenidos y temas generales, trabajo, alfabetización en el hogar, educación en familia, ciudadanía, etc., con prioridades que dependen de las necesidades específicas de cada país. Asimismo, se asumió la convicción de que el aprendizaje y la educación de adultos dotan a las personas de los conocimientos, capacidades, habilidades, competencias y valores necesarios para ejercer y promover sus derechos; siendo también un factor indispensable para el logro de la equidad y la inclusión, para mitigar la pobreza y para construir sociedades equitativas, tolerantes, sostenibles y basadas en el conocimiento.

En Argentina, a partir de la LEN (2006), se define a la Educación de Jóvenes y Adultos como una "modalidad del sistema educativo" cuyos objetivos son, por una parte, la alfabetización y el cumplimiento de la obligatoriedad escolar prevista por la normativa a quienes no la hayan completado en la edad establecida reglamentariamente, y por otra parte, brindar posibilidades de educación a lo largo de toda la vida (Art. 46). Respecto a estos propósitos, la Ley de Educación Provincial de Córdoba (2010), agrega un objetivo: "brindar capacitación técnico profesional a la 
población adulta, con el fin de lograr el constante mejoramiento de su formación individual y su integración social" (Ley 9870, Art. 53).

La LEN expuso la necesidad de la ampliación de responsabilidades a otras carteras de gobierno, que garantizaran "articulaciones exitosas" en el marco del desempeño social y laboral de los jóvenes y adultos desde donde se realizan las propuestas formativas. Entre las estrategias que se propuso el Ministerio de Educación se encuentra la articulación con otros ministerios, comprometiéndose a brindar información sobre la oferta y el acceso a la modalidad.

De acuerdo con las exigencias y acreditaciones que el mundo actual del empleo requiere, la LEN prescribió un artículo transitorio (art. 138) para la formulación de acciones concretas para la población con menor grado de escolaridad, destinadas a garantizar la erradicación del analfabetismo y el cumplimiento de la educación obligatoria para la población de 18 años o más que no la haya alcanzado a la fecha de promulgación de la presente ley. De igual manera, los Programas de Empleo del Ministerio de Trabajo, Empleo y Seguridad Social, "llevan adelante acciones con fuerte presencia de componentes educativos no formales o formales que articulan sus acciones con la cartera educativa" (Ministerio de Educación, 2008, p.4).

En la provincia de Córdoba, de acuerdo con la estructura y las orientaciones más generales que propone la LEN sobre EDJA, la Ley de Educación Provincial № 9870 (2010) también explicitó la necesidad de entablar "convenios de colaboración" con autoridades de otros sectores: "El Ministerio de Educación de la Provincia de Córdoba debe propiciar la firma de convenios de colaboración mutua entre las autoridades educativas con el sector de la producción y el trabajo a fin de favorecer la realización de prácticas profesionales intracurriculares y/o pasantías laborales de los estudiantes con propósito formativo y garantía de planificación y acompañamiento docente" (Ley 9870, Art. 46).

Estos convenios colaborativos se constituyeron en una base fundamental para articular los programas y acciones de educación para jóvenes y adultos con acciones de otros organismos gubernamentales 
referidos al área como también con el mundo de la cultura, de la producción y el trabajo. No obstante, vale destacar que existían acuerdos previos entre el Ministerio de Trabajo y el gobierno de la provincia de Córdoba desde 2004, año en que se firmó el Acuerdo para la implementación del Plan Integral para la Promoción del Empleo Más y Mejor Trabajo (Convenio 36/04).

Las principales normativas nacionales en torno a la EDJA fueron: la Resolución N²2/2007 que instruyó la creación de una "Mesa Federal de Educación de Jóvenes y Adultos"; los "Lineamientos para un Plan Federal de EDJA 2007-2011" para garantizar el cumplimiento de los niveles de obligatoriedad educativa de todas las personas mayores de 18 años; la Resolución № 118/2010 que estableció una "agenda prioritaria" de definiciones políticas y técnicas para avanzar en nuevas formas de organización institucional y curricular de la modalidad en los gobiernos educativos jurisdiccionales.

Todas estas orientaciones políticas, se inclinaron al trabajo intersectorial, a la transversalidad de la modalidad, a los esfuerzos concurrentes entre las comunidades educativas y las distintas carteras políticas, en pos de articular esfuerzos para ajustar las estrategias a las necesidades de los sujetos, generar espacios de participación y potenciar el uso de los recursos. Estos lineamientos y acciones, configuraron el marco regulador en el cual se inscriben las políticas provinciales para la modalidad.

Esta forma de entender la política educativa, que convoca a diferentes sectores para la articulación de acciones, encuentra puntos de convergencia con la "estrategia de territorialidad" de la política de empleo del período 2003-2015, una herramienta que pretendió congregar agentes y agencias de los más diversos ámbitos para hacer frente a las dificultades de sostenimiento y armonización que presentan las políticas de inclusión en los espacios locales de implementación.

Un reconocimiento existió en parte por las reuniones internacionales, y en parte por los estados que parecieron responder a los nuevos escenarios sociales y quizás también a la presión simbólica de grandes contingentes de 
jóvenes y adultos excluidos de la educación. De esta manera, la EDJA se fue convirtiendo en un actor reconocido como estratégico en el desafío de la obligatoriedad educativa y como parte vital del engranaje que conforma la maquinaria de la inclusión educativa.

La política educativa a través de numerosas leyes y normativas, instaló nuevas visiones sobre la educación como derecho y obligación, el respeto por la diversidad y las diferencias, la educación para toda la vida, para el ejercicio de la ciudadanía, entre otras. Pero más allá de los nuevos discursos que se inauguraron y se revitalizaron, es necesario poder analizar las brechas que se presentaron entre los imperativos de inclusión desde el Estado y lo que ocurrió en las instituciones y en las prácticas efectivas. En este sentido, una tensión que atraviesa a los mandatos de las políticas, es atender las particularidades locales en la puesta en práctica de las acciones, un "proceso de recreaciones" (BALL, 2011) en un contexto local concreto.

Hernández Flores $(2007,2008)$ señala que la escuela de adultos es un escenario de constitución de significados para los sujetos que asisten a ella. Las características físicas y edilícias de la escuela, la distribución de los tiempos y recursos, y las prácticas pedagógicas que efectivamente suceden, están ligadas a condiciones estructurales que inciden en los procesos de inclusión que se proponen los programas estatales. La EDJA muchas veces ocupa un lugar relegado en las políticas educativas, que se traduce localmente en una deficiente infraestructura y en un espacio de formación en condiciones de exclusión social y educativa:

"Son múltiples los entrecruzamientos de estas políticas en la escala local. La gran tradición en las prácticas de EPJA en las comunidades, las políticas gubernamentales mencionadas y los rasgos del contexto se entrecruzan para generar espacios singulares habitados por agentes sociales que imponen la carga de sus propias vivencias al tiempo que son condicionados por la diferencia y la desigualdad (...) asumimos que al tratar de situar las prácticas educativas de EPJA implica necesariamente el acercamiento a las textualidades diversas de agentes y tiempos entrelazados en momentos particulares" (HERNÁNDEZ FLORES, 2008, p.3). 
En este sentido, las estrategias políticas de inclusión educativa, implican romper con los paradigmas tradicionales entre pobreza y escolarización, para partir de las necesidades concretas de los jóvenes y adultos, no sólo de las ideas preconcebidas en el contexto en que se diseñan las políticas.

\section{LA EDJA EN UN PROGRAMA DE EMPLEO: re-contextualizaciones de las políticas en una experiencia local}

A partir del 2008, el Ministerio de Trabajo, Empleo y Seguridad Social (MTEySS) de Argentina, creó el Programa Jóvenes con Más y Mejor Trabajo (Programa Jóvenes). Los destinatarios del programa fueron hombres y mujeres de entre 18 y 24 años de edad, desempleados, que no completaron sus estudios primarios $y / 0$ secundarios. Su propósito fue generar oportunidades de inclusión social a través de acciones integradas para identificar el perfil profesional en el cual deseen desempeñarse, finalizar su escolaridad obligatoria, realizar experiencias de formación y/o de prácticas en ambientes de trabajo, iniciar una actividad productiva de manera independiente o insertarse en un empleo.

Las certificaciones educativas constituyen uno de los objetivos centrales del Programa Jóvenes. Fueron propuestas como una articulación necesaria con las instituciones educativas provinciales y sus servicios para la formación y certificación de estudios generales para adultos accesibles en términos de vacantes, modalidades de cursada, y la provisión de materiales didácticos y curriculares a ser utilizados.

En la provincia de Córdoba, se implementó por primera vez el Programa Jóvenes, en la localidad de Villa Allende, durante la segunda mitad del año 2009, reeditándose varias veces en años sucesivos.

Desde el estudio realizado, el componente educativo del programa de empleo se convirtió en una opción que logró un suceso notable. Según datos de la coordinación del Programa Jóvenes en la Oficina de Empleo, durante 
las 3 primeras fases de implementación (2009-2010)6, de un total de 700 jóvenes inscriptos al programa, 322 jóvenes se inscribieron en la escuela de jóvenes y adultos, en distintos trayectos para finalizar los estudios obligatorios. Fue la modalidad semipresencial (a distancia) la que más alumnos concentró en el nivel medio.

Las expectativas de los jóvenes del programa en torno a lo educativo, aparecían ligadas a condiciones familiares atravesadas por múltiples desigualdades y la posibilidad de revertir historias de exclusión vivenciadas por sus padres. En otros casos -donde las/los jóvenes eran padres/madres y/o jefes de familia- las aspiraciones educativas estaban vinculadas a la intención de forjar un futuro para sus hijos.

Muchos de los jóvenes que participaban del programa se desenvolvían en el sector más precario del mercado laboral, la mayoría trabajaba desde que eran niños. Esos recorridos y experiencias posibilitaron el desarrollo de ciertas estrategias (entre ellas retomar los estudios a través de la escuela de adultos) para conseguir mejores oportunidades dentro de ese mercado laboral que se les presenta restringido.

La opción del Programa Jóvenes para finalizar la escolaridad obligatoria, es una de las estrategias de los jóvenes y adultos hacia el acceso al "trabajo decente" (como trabajo asalariado, de calidad, con prestaciones básicas y seguridad social) que responda a diversas necesidades vitales. La educación -en ese sentido- era percibida como un puente hacia mejores condiciones de trabajo y mejor remuneración. "Volver a la escuela" o "terminar la escuela", se percibía como algo central para la transición idealizada y deseada hacia un "mejor" empleo, a través de recursos y capitales que permitirían revertir historias de exclusión, condiciones e inserciones precarias de las que forman parte.

La Educación de Jóvenes y Adultos en la provincia de Córdoba, ofrece alternativas para finalizar la educación básica obligatoria: la

\footnotetext{
6 Primera fase: Junio-Agosto de 2009; Segunda fase: Octubre-Diciembre de 2009; Tercera fase: Junio- Agosto de 2010.
} 
modalidad presencial y la modalidad semipresencial7, que comparten parte de los docentes; y el Plan FINES (Plan Finalización de Estudios Primarios y Secundarios) $^{8}$ que tiene una modalidad de gestión conjunta entre el Ministerio de Educación de la Nación y los Ministerios de Educación de las provincias, a través de la elaboración de Convenios. Todos estos trayectos educativos dependen de un Centro Educativo de Nivel Medio de Adultos (CENMA) de base.

El ingreso de los jóvenes del programa de empleo a la escuela media de adultos, en el espacio local estudiado, se realizó a través de una apertura de matrícula especial en el mes de agosto de 2009. Esto produjo un impacto en la institución escolar, particularmente en la modalidad semipresencial que era el sistema viable para realizar trayectos a distancia.

El sistema semipresencial y - en menor medida - el Plan Fines, fueron los trayectos más elegidos, bajo el supuesto que eran itinerarios "más cortos" y "más fáciles". Ambos se basan en una metodología de tutorías. Dos veces a la semana se realiza un asesoramiento sobre las dudas que plantea el trabajo con los módulos, que son 12 en total (incluído el módulo introductorio). Plan Fines utiliza como referentes los módulos del sistema semipresencial, elaborados por el Ministerio de Educación de la Provincia de Córdoba.

El estudiante se lleva el módulo, lo estudia, hace el trabajo práctico y si lo aprueba rinde la materia. Si necesita explicaciones acude a la escuela, pero las tutorías no son obligatorias: "Los módulos se estructuran en apartados referidos a las áreas o disciplinas, cada uno de los cuales consta básicamente de los siguientes ítems: índice, introducción, desarrollo de contenidos, actividades, claves de corrección, trabajo práctico integrador y bibliografía, aunque algunos de estos componentes, en especial las

\footnotetext{
7 Programa de Educación Secundaria para Jóvenes y Adultos semipresencial.

8 El Plan Fines no es estrictamente una oferta de la EDJA, pero es una de las vías desde dónde se ofrece la finalización de estudios obligatorios. Es un programa educativo destinado a los jóvenes y adultos, mayores de 18 años, que no iniciaron o no terminaron la primaria o la secundaria.
}

Revista Exitus, Santarém/PA, Vol. 8, №3, p. 370 - 395, SET/DEZ 2018. 
actividades y claves de corrección suelen no estar presentes en algunas disciplinas o áreas" (ACIN, 2013, p.219).

Desde una investigación reciente, Paolasso (2018) manifiesta que la propuesta pedagógica del Plan Fines, adopta el criterio de "flexibilidad", a través de la estructura modular que posibilita el tránsito por áreas y disciplinas con aprobaciones parciales por módulos. En función de ello, los estudiantes pueden iniciar, discontinuar y retomar su itinerario formativo en función del tiempo disponible y su trayectoria educativa. Otro criterio adoptado es el de "apertura" hacia la realidad de cada estudiante, según el proceso de contextualización de los contenidos de enseñanza.

Las tutorías son concebidas como un encuentro entre jóvenes y adultos, en el marco de un espacio "abierto y dialógico", en el que se despliegan expectativas, saberes y conocimientos. Tanto las tutorías como la estructura curricular modular, pretenden acompañar la trayectoria educativa de los estudiantes y la propuesta de mejora se relaciona con poder acompañar estos diversos itinerários, favorecer el acompañamiento y culminación de los estudios secundários. En los documentos nacionales, el tutor es un educador concebido como un mediador y un referente del conocimiento para los estudiantes, que toma como desafío central la construcción de un vínculo pedagógico, basado en la "confianza mutua" con el estudiante (PAOLASSO, 2018).

La modalidad semipresencial en la escuela estudiada, habitualmente tenía pocos alumnos (entre 8 y 10 alumnos), el impacto de la matrícula especial para los estudiantes del Programa Jóvenes fue percibido como "avalancha" y produjo algunas alteraciones en el trabajo con los módulos, suprimiéndose la supervisión de ciertos contenidos debido al gran número de jóvenes que comenzaron a asistir a las tutorías. Este hecho hizo que los profesores debieran adecuar las tutorías y canalizar las dudas a través de distintas estrategias operativas por ser un sistema basado casi exclusivamente en materiales impresos.

A su vez, el convenio con el Programa Jóvenes no contempló la inclusión de nuevos profesores para el sistema de tutorías que propone. Por 
considerarse "modalidad a distancia" el docente tutor se hace cargo de todos los módulos, con alumnos con diferentes trayectorias escolares y tiempos diversos de aprendizaje.

El ingreso de los jóvenes del programa, multiplicó las dificultades de los docentes para llevar adelante tutorías de hasta 50 alumnos, produciéndose una sobrecarga de trabajo.

Los jóvenes eligieron masivamente la opción a distancia, pero después no se sostuvieron en el mecanismo de la tutoría porque eran estudiantes que necesitaban de la interacción en el aula, de la presencia de los compañeros y del profesor, precisaban asistencia permanente y una formación escolar con determinada cantidad de horas diarias. Cuestiones que cambian radicalmente el problema del acceso y de la construcción del conocimiento.

Los profesores llegaron a diciembre sin poder atender las consultas de todos, hecho que generó choques, molestias y quejas por la sobrecarga de trabajo con los módulos. Esto fue un elemento que contribuyó a la deserción del grupo al inicio del año siguiente.

Otra de las principales problemáticas del ingreso de los jóvenes del programa se dio desde el punto de vista espacial. El inconveniente sobre el uso de los espacios también visibilizó situaciones donde se reforzaron las diferencias entre los jóvenes regulares de la escuela (que tenían prioridad) y aquellos que accedían por el canal que ofrecía el Programa Jóvenes.

Para el sistema semipresencial se utilizó un salón comedor que oficiaba de aula, sin pizarrón, sin mobiliario apto para una escuela. Se observaron varias restricciones que aparecen naturalizadas por distintos agentes institucionales, expresando que la permanencia escolar -en definitiva- tiene que ver con la "adaptabilidad" y la "acomodación" de los sujetos a estas circunstancias aparentemente cotidianas e inevitables.

Las restricciones en el uso de los espacios se dieron específicamente en el acceso a aulas, a mobiliario escolar y a la sala de Informática. Estas limitaciones condicionaron la calidad de los procesos educativos en la 
"vuelta a la escuela" e incidieron -fundamentalmente- en la posibilidad de "terminar" el trayecto.

A través del convenio con el programa de empleo, la escuela recibió jóvenes con diferentes problemáticas, entre ellas, jóvenes judicializados, con libertad asistida; con problemas de aprendizaje, con capacidades diferentes, jóvenes atravesados por múltiples desigualdades sociales, entre otras. Las diferencias se plantearon desde el inicio, entre los alumnos "estables" de la escuela y los nuevos ingresantes por el Programa Jóvenes ("intrusos"), en su mayoría habitantes de un barrio popular de la ciudad (denominado "villa" por varios entrevistados).

Estos jóvenes provenían con marcas sociales arraigadas en la localidad, debido a su condición socio económica y al barrio de procedencia, un espacio emblemático de la pobreza de la ciudad, "el más inseguro", según algunos docentes.

Se produjeron resistencias iniciales desde una separación taxativa entre los estudiantes regulares y los "nuevos" que ingresaban por el programa. Un grupo de profesores se negó enfáticamente a la incorporación de los jóvenes en la escuela. Entre algunos de los motivos expresaron: "no vienen a la escuela a estudiar, vienen porque les pagan", "vienen acá por el plan", "estos chicos siempre son un problema", entre otros.

Estas expresiones dejaron al descubierto, la deslegitimación social que pesa sobre ciertos jóvenes y adultos desde el propio espacio escolar local. Sin embargo, esta mirada estigmatizante y descalificadora sobre los sectores subalternos que reciben ayudas económicas del Estado, no es novedosa y tiene una historia de varios años en nuestro país. El uso de planes de empleo por parte de las organizaciones de desocupados en el año 2001, en un contexto de crisis total, fue convertido en una marca social por el gobierno nacional9 (PACHECO, 2004), que se fue solapando desde los discursos oficiales hasta instalarse en la opinión pública y en el imaginario social,

\footnotetext{
9 Bajo la presidencia de Fernando de la Rúa (1999-2001) a través de su Ministra de Trabajo
} Patricia Bullrich. 
impregnándose, naturalizándose y reconfigurándose con los años de distintas maneras, en distintos ámbitos y hacia diferentes sujetos sociales y colectivos.

Otro grupo de profesores expresaron un discurso alternativo respecto a estas representaciones al poner en evidencia el prejuicio de sus pares con respecto a los planes sociales y-particularmente- a los alumnos que reciben ayudas económicas del Estado para finalizar los estudios. Estos docentes se manifestaron en desacuerdo, resaltando lo "fascista", "conservador" y "retrógrado" de ese pensamiento que es reforzado de forma recurrente en los medios de comunicación y que está vigente en el discurso de algunos docentes, que no advierten las contradicciones que supone esto para su labor como trabajadores estatales, en el marco de una política de inclusión educativa.

Las imágenes y percepciones sobre los participantes del programa, eran representaciones que circulaban socialmente en torno a la marginalidad, a la pobreza y a todo lo que éstos jóvenes condensan en sus historias de vida: no haber terminado la educación básica obligatoria, no tener trabajo, ser pobre, vivir en la villa, pertenecer a un programa de empleo.

Muchos de los conflictos y resistencias generadas hacia ellos, además de su barrio de origen y la supuesta peligrosidad que ello suponía, se relacionaban con que parte del cuerpo docente de la institución tenía una idea de alumno que no existe, un sujeto alumno idealizado y añorado de la EDJA que no se correspondió con el que efectivamente se matriculó.

\section{INCLUSIONES QUE EXCLUYEN. CONSIDERACIONES FINALES}

La política pública no es resultado de un proceso lineal, coherente y necesariamente deliberado de diseño o formulación, sino que es objeto de un proceso social y político que configura un campo en disputa. En este sentido, las políticas -su diseño y desarrollo- no son un espacio neutro jurídico o administrativo sino una "arena política" en la que convergen, luchan y conciertan las fuerzas políticas. Una política es - en un doble sentido - un 
"curso de acción", es el curso de acción deliberadamente diseñado y el curso de acción efectivamente seguido (AGUILAR VILLANUEVA, 2003).

En tanto producto del "juego de poder" en la arena política, son construcciones sociales donde las decisiones no se conciben como resultado de un solo actor (racionalmente puro), sino de interpelaciones, confrontaciones y consensos entre distintos actores o grupos intervinientes, con distintos grados de participación. Las políticas públicas son parte de un proceso dinámico y complejo que está constantemente en movimento. En este sentido, Ball (2002) manifiesta que las políticas son redefinidas a través de complejos procesos de "recontextualización" en los distintos niveles y contextos donde se expresan y se implementan. Las traducciones, las reinterpretaciones y recreaciones de la política son múltiples.

En Argentina, el concepto de inclusión se convirtió -a partir de 2004- en una categoria central de las políticas sociales, laborales y educativas elaborados por organismos internacionales como UNESCO y UNICEF, que se orientaron a grupos sociales empobrecidos. No obstante, es importante remarcar que "su uso retórico, renovado y generalizado apunta a generar "prácticas inclusivas" así como conformar "instituciones inclusoras", presuponiendo que la sola enunciación asegura un cambio en las situaciones cotidianas (...) "cambiar" de paradigma no conlleva en absoluto un cambio en las prácticas y procesos de exclusión que se documentan a diario en las instituciones educativas y en la sociedad. Cambiar estas prácticas implica, en primer lugar, poder visibilizarlas y reconocerlas como tales" (SINISI, 2010, p.11-13).

Según Santillan (2007), también es frecuente en la literatura especializada, que los itinerarios escolares de niños y jóvenes sean referidos sólo a las "entradas" y "salidas" de la escuela. Sin embargo, las trayectorias educativas implican un recorrido "experiencial" y de "apropiación" de un conjunto de prácticas producidas en el marco de tramas densas de intervención que incluyen a diversos actores sociopolíticos que rebasan los espacios específicamente pensados para la escolarización. 
Rockwell (1995) sostiene que en la escuela, las normativas oficiales son recibidas y reinterpretadas por los sujetos desde una "experiencia escolar" que participa de forma dinámica entre las normas y la realidad cotidiana. La autora manifiesta que dicha experiencia escolar, posee dimensiones que organizan las prácticas institucionales de la escuela: el uso del tiempo y del espacio, la formación de grupos y su participación, las relaciones y costumbres aprendidas que se proyectan en el entorno social; la definición escolar del trabajo docente y su vinculación con las formas de enseñanza; entre otras.

En este sentido, el acceso a los espacios y recursos en los cuales se "tramitan" sentidos alrededor de la educación, implica toda una "experiencia formativa" tanto para los estudiantes como para sus familias. El análisis centrado en los "contextos de interacción", permite situar la construcción de sentidos en torno a la educación en matrices sociales más amplias, y no ajustadas a relaciones "interpersonales" ni "valores culturales" estancos (SANTILLAN, 2007).

En el caso estudiado, la inclusión educativa de los jóvenes del programa fue traducida localmente como un problema. Pero no todos los docentes se posicionaron del mismo modo frente a los condicionamientos adversos de los alumnos. Para algunos docentes y agentes institucionales, su barrio de pertenencia, sus expresiones y sus modos de actuar eran un atributo estigmatizante y negativo.

Existen una serie de prejuicios y representaciones negativas sobre quienes hacen uso de las ayudas económicas en el marco de un programa público, se produce una distinción entre jóvenes que acceden a la escuela por los canales "normales" y aquéllos que lo hacen a través de "un plan". Esto es visto de manera despectiva y como algo injusto por un sector de la comunidad educativa. No obstante, para otros docentes era una preocupación más relevante el acompañamiento de las tutorías, la calidad de los conocimientos y procesos escolares ofrecidos para jóvenes que atraviesan múltiples desigualdades, representando esto un gran desafio. 
Las diversas formas de etiquetamiento, son condicionamientos de los procesos de inclusión educativa, actúan como un filtro selectivo que se expresa en la limitación del uso de los espacios, en la resistencia a su llegada, en la estigmatización asociada a su lugar de residencia, a la apariencia física, a las formas de hablar y comportarse.

El criterio selectivo incide sobre los objetivos de inclusión del programa, los trastoca. Es clave en la configuración de itinerarios desiguales recorridos en la escuela y en las nuevas exclusiones producidas por la supuesta falta de adaptabilidad del sujeto "intruso", evidenciadas a través de la no terminalidad, del abandono, de la deserción, del desgranamiento de la matrícula.

Los mecanismos selectivos encubiertos de la institución escolar, forman parte de un engranaje que funciona a partir de la naturalización de condiciones y prácticas que se suponen están asociadas a las capacidades de adaptación del sujeto, borrando su incidencia sobre los "fracasos" en la escolaridad.

Son recurrentes las imágenes que se construyen y circulan socialmente sobre las personas pobres y otros grupos subalternos que son despectivas y degradantes para ellos. Tales representaciones son casi siempre producidas para la "legitimación de la exclusión social". Desde este lugar, la dinámica cultural de la escuela no puede pensarse por fuera de las disputas entre grupos sociales y del juego de poder de las distintas culturas, donde se evoca una cultura dominante (THISTED y otros, 2007).

La "inclusión desigual" como es denominada por Sen y Kliksberg (2007), expresa que a pesar de las múltiples iniciativas privadas y programas estatales orientados a la inclusión de los sujetos en la infraestructura de una región en particular, no se ha logrado que todos las personas tengan las mismas oportunidades de aprovechar estos recursos y por ello muchos terminan siendo "incluidos" de forma desigual en muchos programas lo que constituye -en definitiva- una forma de exclusión.

En este sentido, también cobra relevancia la noción de "exclusiones incluyentes" como "proceso mediante el cual los mecanismos de exclusión 
educativa se recrean y asumen nuevas fisonomías, en el marco de dinámicas de inclusión o inserción institucional que acaban resultando insuficientes 0 , en algunos casos, inocuas para revertir los procesos de aislamiento, marginación y negación de derechos que están involucrados en todo proceso de segregación social, dentro y fuera de las instituciones educativas" (GENTILI, 2009, p.33).

La finalización de estudios obligatorios en el marco de inclusión educativa propuesta desde el Programa Jóvenes a través de la escuela de adultos, permitió el acceso (la inserción), pero no generó condiciones de base que favorecieran la calidad de los procesos de aprendizaje y la permanencia de los jóvenes y adultos en el sistema educativo, un ejemplo de esto es la flexibilización de la tarea docente de la modalidad semipresencial al no garantizar mayor cantidad de profesores que realicen las tutorías y el acompañamiento requerido, y el abandono masivo al año siguiente por parte de los jóvenes.

Todos los elementos analizados develan la difícil implementación de la inclusión educativa en el espacio local donde se traducen las políticas y se recrean las letras de las normativas, fundamentalmente para aquellos jóvenes y adultos que - perteneciendo a un programa público de empleo optan por retomar los estudios formales a través de las distintas ofertas de terminalidad educativa, recibiendo la ayuda económica del Estado.

En el caso, volver a la escuela a través de un programa socio educativo opera como una marca que estigmatiza y señala una diferenciación social, impactando esto en el trato recibido por las autoridades, en el uso de los espacios y los recursos, y cercenando la posibilidad de visualizar un horizonte educativo común. Estos son datos relevantes para reconocer las consecuencias negativas que las segregaciones, estigmatizaciones y distinciones tienen en la cuestión social, en la subjetividad de los estudiantes y en la construcción de trayectorias educativas y laborales desde una perspectiva de derechos.

En síntesis, la inclusión educativa en el espacio local estudiado, se traduce en una relación mediada y disputada que se convierte en 
ocasiones - como la expuesta - en excluyente, pero también encuentra puntos de convergencia en una trama de relaciones dinámicas (divergencias, conflictos, convergencias, consensos), dependiendo sus sentidos y resultados de los condicionantes institucionales (acceso a información, mobiliario, recursos humanos, presupuestos, visiones sobre los sujetos y la política), de la vinculación entre los sujetos responsables y participantes (afectividad, lazos, etiquetamiento, estigmatización), y de las múltiples vinculaciones con las limitaciones estructurales del contexto económico, productivo, social y político.

\section{REFERENCIAS}

ACIN, A. La educación secundaria de adultos en la actualidad. Un estudio comparado entre Córdoba (Argentina) y Cataluña (España). Tesis doctoral. Universidad de Barcelona, 2013.

AGUILAR VILLANUEVA, L. La hechura de las políticas públicas. Porrúa, México, 2003.

BALL, S. Grandes políticas, un mundo pequeño. Introducción a una perspectiva internacional en las políticas educativas. En Narowdosky, M. comp. Nuevas tendencias en políticas educativas: estado, mercado y escuela. Ed. Granica S.A. Buenos Aires, 2002.

BALL, S. Política social y educativa, empresa social, hibridación y nuevas comunidades discursivas. Propuesta Educativa, Número 36 - Año 20 - Nov, 2011 - Vol 2 - Págs. 25 a 34. FLACSO, Argentina, 2011.

FILMUS, D. Educar para el mercado. Escuela, universidad y ciencia en tiempos de neoliberalismo. Buenos Aires. Octubre editorial, 2017.

FILMUS, D. La educación y el trabajo para la inclusión social de los jóvenes. Revista de Trabajo. Año 6. Número 8. Enero / Julio 2010. Ministerio de Trabajo, Empleo y Seguridad Social de la Nación. Argentina, 2010.

GENTILI, P. Marchas y contramarchas. El derecho a la educación y las dinámicas de exclusión incluyente en América Latina. Revista Iberoamericana de Educación, № 49. pp. 19-57, 2009. Organización de Estados Iberoamericanos, 2009.

HERNANDEZ FLORES, G. "En torno a la construcción de significados de jóvenes en alternativas educativas gubernamentales", En Cuadernos de Educación, año VI, № 6, Córdoba: CIFFYH, 2008. 
HERNÁNDEZ FLORES, G. Políticas educativas para la población en estado de pobreza. México: CREFAL, 2007.

KRICHESKI, M. Formatos escolares alternativos y desigualdades sociales. Resultados de un estudio y reflexiones en torno al derecho a la educación secundaria. En: De Prácticas y Discursos. Cuadernos de Ciencias Sociales Año 3 no. 3. 201 4. Resistencia: Universidad Nacional del Nordeste, 2014.

PACHECO, M. Del piquete al movimiento. Parte 1: De los orígenes al 20 de diciembre de 2001. Cuadernos de la Fisyp, Fundación de Investigaciones Sociales y Políticas. N 11. Buenos Aires, 2004.

PAOLASSO, Y. "Finalización Educativa de Jóvenes y Adultos. El caso del Plan 'Fines' en Caleta Olivia, Santa Cruz (2008-2013)". Tesis de maestria. UNPA, 2018.

ROCKWELL, E. La escuela cotidiana. México: Fondo de Cultura Económica, 1995.

SANTILLÁN, L. "La "educación y la escolarización" infantil en tramas de intervención local: una etnografía en los contornos de la escuela". Revista mexicana de Investigación educativa no 34. México: Consejo Mexicano de Investigación Educativa (COMIE), 2007.

SEN, A. Exclusión e Inclusión. En A. Sen, B. Kliksberg (Eds). Primero la Gente. Una Mirada desde la ética del Desarrollo a los principales problemas del Mundo Globalizado (págs.2 -42). Barcelona: Ediciones Deusto, 2007.

SINISI, L. Integración o Inclusión escolar: ¿ un cambio de paradigma? Boletín de Antropología y Educación, № 01. Buenos Aires: UBA, 2010.

THISTED, S; DIEZ, M.A; MARTíNEZ, M.E; VILLA, A. Interculturalidad como perspectiva política, social y educativa. Mayo 2007. Dirección de Modalidad de Educación Intercultural. Provincia de Buenos Aires, 2007.

TIRAMONTI, G. Una aproximación a la dinámica de la fragmentación del sistema educativo argentino. Especificaciones teóricas y empíricas. En Tiramonti, Guillermina y Montes, Nancy (comps.). La escuela media en debate. Problemas actuales y perspectivas desde la investigación. Buenos Aires, Manantial/FLACSO, 2008.

TIRAMONTI, G. Variaciones del formato escolar. Límites y posibilidades de la escuela media. Colección "Pensar la Educación". Buenos Aires, FLACSO. Área Educación, 2011.

UNICEF. Acerca de la obligatoriedad en la escuela secundaria argentina. Análisis de la política nacional. Buenos Aires: UNICEF, 2012. 
ZIEGLER, S. Entre la desregulación y el tutelaje: ¿̇hacia dónde van los cambios en los formatos escolares? En Tiramonti, Guillermina. Variaciones del formato escolar. Límites y posibilidades de la escuela media. Colección "Pensar la Educación". Buenos Aires, FLACSO. Área Educación, 2011.

Recebido em: Abril de 2018 Aprovado em: Julho de 2018 